\title{
Introduction to the Stability of Rational Expectations Equilibrium
}

\author{
L. E. Blume \\ Department of Economics, University of Michigan, Ann Arbor, Michigan 48109 \\ M. M. BRAY \\ Faculty of Economics and Politics, \\ Cambridge University, Cambridge CB39DD, England \\ AND \\ D. EASLEY
}

Department of Economics, Cornell University, Ihaca, New York 14853

Received July 1, 198 1

\begin{abstract}
This paper surveys the literature which examines the stability of the expectations that agents are assumed to have in a rational expectations equilibrium (REE). This issue is more complex than the usual statistical estimation problem because the relationship between observable variables and payoff relevant variables is endogenous. One approach taken in the literature yields convergence to a REE but requires agents to have extensive knowledge about the structure and dynamics of the model that prevails while they learn. A second approach does not assume that agents have correctly specified likelihood functions and finds that REE may not be stable. Journal of Economic Literature Classification Numbers: 021, 022, 026.
\end{abstract}

The usual justification for the rational expectations hypothesis is that in the absence of rational expectations agents must be systematically making mistakes and should therefore modify their behavior until they have obtained rational expectations. This intuition is correct for a Bayesian or classical statistician who is estimating parameters of a known functional form with observations which are exogenously determined. However, it does not directly apply to rational expectations models. In such models the relationship between observable variables and the payoff relevant states that agents must predict is endogenous. The relationship that would result in a rational expectations equilibrium is not necessarily the relationship generating the data that agents use in their learning process. Because of this 
endogenity the adjustment of expectations is a complex problem. The work on this problem can be thought of as an examination of the stability of the expectations that agents need if a rational expectations equilibrium is to result.

Although there have been numerous approaches to this problem there are two frameworks that characterize most of the literature. In one framework agents are learning about parameters of a distribution by using a correctly specified likelihood function. These agents will learn the true value of the parameters through repeated applications of Bayes Theorem. In this framework agents are uncertain about certain features of their world, for example about other agents' risk aversion. However, they understand what is happening well enough to form rational expectations based on their prior probabiliy assessments of the things they are uncertain about, and the information they observe as time progresses. They revise their probability assessments in a Bayesian fashion, using a correctly specified likelihood function. This framework embodies fully rational learning, but is extraordinarily demanding in terms of the information, understanding, and calculating ability of agents.

In the other framework agents are not assumed to have correctly specified likelihood functions. The likelihood functions used are not a correct specification of the process generating the data that agents receive, but in most cases the model that agents use during the learning process includes a correct specification of the rational expectations equilibrium. This second framework is much less informationally demanding than the first, but the results are open to the criticisms that the learning process is not itself rational and that the statistical procedures used are limited because they do not allow for hypothesis testing and model revision.

The first framework includes papers by Arrow and Green [1], Blume and Easley [4], Bray and Kreps [6], Cyert and De Groot [8], Friedman [10], Frydman [11], Kihlstrom and Mirman [13, Sect. 3], Taylor [15], and Townsend [16, 17]. Friedman, Kihlstrom and Mirman, and Taylor study examples in which the relationship between the variables agents observe, and those they wish to predict, is unaffected by expectations. In these cases standard theorems on the asymptotic properties of estimators establish that expectations converge to rationality. Frydman [11] shows that in a model in which outcomes depend only upon average point predictions, and that average is observable, econometric estimation based on a correctly specified model, eventually yields rational expectations. Arrow and Green, Blume and Easley, Bray and Kreps, Cyert and De Groot, and Townsend analyze models in which expectations affect outcomes, and are unobservable. In these models agents are given likelihood functions which are a correct description of the data generating process that results when these likelihood functions are used. In each of these cases convergence to rational expectations follows directly 
from the asymptotic properties of Bayesian estimators. As Townsend points out, the situations considered are Nash equilibria; each agent's specification of the likelihood function is correct given his own specification and those of all the other agents. If some agents specified their likelihood functions differently, the specifications which were correct in the Nash equilibrium would become incorrect.

The concept of a Nash equilibrium in learning strategies has much to commend it. Any other learning process is to some degree ad hoc; if some or all of the agents are learning by using mis-specified models, ai some stage they should realize this and change the specification. Nash equilibria in learning strategies are rational expectations equilibria in which agents take into account their uncertainty about features of the world which they are assumed to know in standard models of rational expectations equilibria. However, Nash equilibria in learning strategies are liable to be considerably more informationally demanding than conventional rational expectations equilibria, as agents require extensive knowledge about the structure and dynamics of the model that prevails while they learn. There may also be problems with the existence of equilibrium. Thus, while this approach yields convergence to a conventional rational expectations equilibrium, its extreme informational demands make it an unsatisfactory answer to the initial question of how agents learn how to form rational expectations.

The second framework includes papers by Blume and Easiey [3], Blanchard [2], Bray [5], Brock [7], Cyert and DeGroot [8, Section titled 'An Inconsistent Example'], DeCanio [9], and Radner [14]. Here the outcome depends on the specific learning process, parameter values and priors. In some cases rational expectations equilibria are stable or at least locally stable and in other cases they are unstable.

Within this framework two different approaches have been taken to the process of expectation revision. One approach (Bray (Proposition 4), Blanchard, Brock, DeCanio, Radner) assumes that agents use the same forecasting rule for a long time, meanwhile estimating the relationship between the variables they wish to forecast and the variables they base their forecast on, (or in the case of Brock's deterministic model whilst they are learning how the rate of entry into an industry is related to the size of the industry). When the estimates have reached their probability limits, all the agents simultaneously drop their previous forecasting rule and adopt a new one based on the estimated coefficients derived from data from the period during which the previous forecasting rule was in force. They then reestimate the model, and eventually change the forecasting rule again in the same way. This approach simplifies the problem as the estimates used in the forecasting rule at each stage are deterministic, even when the underlying model is stochastic. However, this approach technically requires that all agents wait an infinite number of dates before revising their forecasting rule. 
Blume and Easley, and Bray (Proposition 5) assume that agents modify their forecasting rule every time they observe a new data point. Blume and Easley examine a general equilibrium model of an exchange economy in which each agent considers a finite collection of models, one of which is a correct description of the rational expectations equilibrium. They show that under a Bayesian type of learning process the rational expectations equilibrium is locally stable, but that nonrational equilibria may also be locally stable. Bray examines an asset market model where traders apply ordinary least squares estimation to a model which is mis-specified while they are learning, but which is a well specified model of the rational expectations equilibrium. Bray shows that for appropriate values of a stability parameter the situation converges almost surely to the rational expectations equilibrium.

An alternative approach to the adjustment and stability of rational expectations equilibria is taken by Jordan [12]. He works with abstract allocation mechanisms and shows that there is a dynamic adjustment process which achieves a rational expectations equilibrium. He also provides an inference process with which each agent can estimate the conditional distribution of the future state given his private information and the messages generated by repetition of the adjustment process. Jordan shows that if all agents use this procedure they can obtain the knowledge required by the dynamic adjustment process. It should be noted that Jordan's analysis has agents conditioning their expectations on the entirc message and that the number of possible preference profiles is assumed to be finite.

\section{REFERENCES}

1. K. J. Arrow ANd J. R. Green, "Notes on Expectations Equilibria in Bayesian Settings," Institute for Mathematical Studies in the Social Sciences, Stanford University, Working Paper No. 33, 1973.

2. O. BlanchaRD, The non-transition to rational expectations, unpublished manuscript, MIT Department of Economics, 1976.

3. L. E. Blume and D. Easley, Learning to be rational, $J$. Econ. Theory 26 (1982), 340-351

4. L. E. Blume AND D. EASLEY, Rational expectations equilibrium and the efficient markets hypothesis, unpublished, Cornell University, March 1981.

5. M. M. Bray, Learning, estimation, and the stability of rational expectations, J. Econ. Theory 26 (1982), 318-339.

6. M. M. BRAY AND D. M. KREPS, Rational learning and rational expectations, unpublished manuscript, Graduate School of Business, Stanford, August 1981.

7. W. A. BRock, On models of expectations that arise from maximizing behavior of economic agents over time, $J$. Econ. Theory 5 (1972), 348-376.

8. R. M. Cyert and M. H. DeGroot, Rational expectations and Bayesian analysís, J. Pol. Econ. 82 (1974), 521-536. 
9. S. J. DECANIO, Rational expectations and learning from experience, Quart. J. Econ, 92 (1979), 47-57.

10. B. M. Friedman, Optimal expectations and the extreme informational assumptions of rational expectations macromodels, J. Monetary Econ. 5 (1979), 23-41.

11. R. Frydman, "Towards an Understanding of Market Processes: Individual Expectations, Market Behavior and Convergence to Rational Expectations Equilibrium," Discussion paper, C. V. Starr Center for Applied Economics, New York University, April 1981.

12. J. S. Jordan, "Allocation and Prediction in Stochastic Environments: An Elementary Theory," Center for Economic Research, Discussion Paper no. 139, 1981, University of Minnesota.

13. R. E. Kihlstrom AND L. J. Mirman, Information and market equilibrium, Bell $J$. Econ. 6 (1975) 357-376.

14. R. RADNER, Equilibrium under uncertainty, in "Handbook of Mathematical Economics", Vol. II (K. J. Arrow and M. D. Intriligator, Eds.), North-Holland, Amsterdam, in press.

15. J. B. TAYLOR, Monetary policy during a transition to rational expectations, J. Pol. Econ. 83 (1975), 1009-1021.

16. R. M. TOWNSEND, Market anticipations, rational expectations, and Bayesian analysis. Internat. Econ. Rev. 19 (1978), 481-494.

17. R. M. TowNSEND, Forecasting the forecasts of others: Formulation and equilibrium time series models, unpublished, Carnegie-Mellon University, August 1980, revised May 1981. 